\title{
Al-powered pan-species computational pathology: bridging clinic and wildlife care
}

Khalid AbdulJabbar ${ }^{1,2+}$, Simon P. Castillo ${ }^{1,2+}$, Katherine Hughes ${ }^{3}$, Hannah Davidson ${ }^{4,5}$, Amy M. Boddy $^{6}$, Lisa M. Abegglen ${ }^{7,8}$, Elizabeth P. Murchison ${ }^{3,9}$, Trevor A. Graham ${ }^{1,5}$, Simon Spiro ${ }^{4}$, Chiara Palmieri ${ }^{10}$, Yinyin Yuan ${ }^{1,2 *}$

Affiliations:

$6 \quad{ }^{1}$ Centre for Evolution and Cancer, The Institute of Cancer Research, London, UK

7 2Division of Molecular Pathology, The Institute of Cancer Research, London, UK

$8{ }^{3}$ Department of Veterinary Medicine, University of Cambridge, Madingley Road, Cambridge, UK.

$9 \quad{ }^{4}$ Zoological Society of London, London, UK.

$10{ }^{5}$ Centre for Genomics and Computational Biology, Barts Cancer Institute, Queen Mary

11 University of London, Charterhouse Sq, London, UK.

$12{ }^{6}$ Department of Anthropology, University of California Santa Barbara, Santa Barbara, CA, USA.

$13{ }^{7}$ Department of Pediatrics and Huntsman Cancer Institute, University of Utah, Salt Lake City,

14 UT, USA.

15 '8PEEL Therapeutics, Inc., Salt Lake City, UT, USA and Haifa, Israel.

$16{ }^{9}$ Transmissible Cancer Group, Department of Veterinary Medicine, University of Cambridge,

17 Cambridge, UK.

$18{ }^{10}$ School of Veterinary Science, The University of Queensland, 4343 Gatton, Queensland,

19 Australia.

20 +Authors contributed equally. ${ }^{*}$ Correspondence to Yinyin Yuan (yinyin.yuan@icr.ac.uk)

21 Abstract:

22 Cancers occur across species. Understanding what is consistent and varies across species can provide new insights into cancer initiation and evolution, with significant implications for animal welfare and wildlife conservation. We built the pan-species cancer digital pathology atlas (PANCAD) and conducted the first pan-species study of computational comparative pathology using a supervised convolutional neural network algorithm trained on human samples. The artificial intelligence algorithm achieves high accuracy in measuring immune response through single-cell classification for two transmissible cancers (canine transmissible venereal tumour, 0.94; Tasmanian devil facial tumour disease, 0.88). Furthermore, in 18 other vertebrate species (mammalia=11, reptilia=4, aves=2, and amphibia=1), accuracy (0.57-0.94) was influenced by cell morphological similarity preserved across different taxonomic groups, tumour sites, and variations in the immune compartment. A new metric, named morphospace overlap, was developed to guide veterinary pathologists towards rational deployment of this technology on new samples. This study provides the foundation and guidelines for transferring artificial intelligence technologies to veterinary pathology based on a new understanding of

36 morphological conservation, which could vastly accelerate new developments in veterinary

37 medicine and comparative oncology. 


\section{Introduction}

39 Cancers occur with phenotypically similar forms across the tree of life ${ }^{1-4}$. Understanding the conserved and diverged aspects of cancer across species can help answer questions about the origin and fundamental processes of its evolution. Immediate and practical advances from panspecies studies provide new tools and valuable insights into tumorigenesis and cancer resistance ${ }^{5-8}$, leading to improved cancer care for humans and non-human animals. Specifically, transmissible cancers presented in dogs and Tasmanian devils ${ }^{9,10}$ are among the few known naturally occurring clonally transmissible cancers ${ }^{11}$. How transmissible cancers escape immune surveillance remains unclear and is of central importance to understanding their biology and cell to cell interactions.

Despite significant resources in companion animal care, clinical treatments options are limited for a few aggressive cancers in dogs ${ }^{12,13}$ that represent one of the best models of human cancer $^{14}$. Beyond domesticated species, various studies have identified valuable models in wildlife ${ }^{15}$. For instance, the naturally-emerging urogenital carcinoma in California sea lions ${ }^{16}$ and papillomavirus triggering brain tumours in raccoons ${ }^{15}$ are remarkable examples of pathogendriven neoplasms. Animals managed in zoological institutes also exhibit occurrence of neoplastic growth according to several international studies, including, a 10-year survey in the Taipei zoo, Taiwan ${ }^{17}$, a study of cancer development in vertebrates in French zoological parks ${ }^{18}$, a 42-years of mammals necropsy data compilation from the San Diego Zoo, United States ${ }^{19}$, and a report on renal lesions followed by neoplastic and inflammatory responses in captive wild felids in Germany ${ }^{20}$. Studies of these animals can provide unique insights into the biology and evolution of cancer across the tree of life towards improving animal welfare by early detection and helping conserve endangered species ${ }^{21,22}$.

61 Challenges for establishing a unified comparative oncology agenda include sample collection, data management, analysis, and integration ${ }^{23-27}$. These can be tackled by incorporating artificial intelligence $(\mathrm{Al})$ algorithms, which can empower veterinary pathology and help dissect the complexity of cancer across species and scales, from genes to epidemiology. Computational pathology powered by Al has revolutionised the study of human cancers and helped improve our understanding of the immune microenvironment ${ }^{28}$. In contrast to human cancer management, we lack systematic and standardised Al protocols and digital archiving and analysis of samples to study animal cancers; hence, veterinary research has not fully adopted digital pathology ${ }^{25}$ although efforts are being made to move forward internationally adopted guidelines for tumour pathology 27 .

71 Hence, we propose Al has the power to fuel pan-species tumour histology and efficiently

72 manage data-related bottlenecks. Thus far, computational pathology in the study of non-human

73 cancers, and non-human pathology in general, is very limited ${ }^{24,25}$. Convolutional neural networks

74 have been applied to detect mitotic activity from histological slides of canine cancers ${ }^{13,29}$. In

75 sheep, deep learning has been employed to delineate growth phases of mammary

76 development ${ }^{30}$. Other machine learning techniques have been used to classify a common

77 gastrointestinal disease in cats ${ }^{31}$. Along with computational pathology, incorporating $\mathrm{Al}$ into the

78 veterinary practice of imaging techniques such as CT scans, magnetic resonance imaging, and 
positron emission tomography ${ }^{32}$ encourages the development of integrative clinical care. Such an integrative approach promises to direct precision medicine in veterinary oncology by tailoring strategies for individual patients. It includes classifying patients who differ in their treatment response and/or prognostic outcomes.

In this work, we explore and exploit the conservatism of cell morphology in neoplasias across species by applying an $\mathrm{Al}$ tool trained in human lung cancer ${ }^{33}$ (Fig 1). We evaluate the accuracy of this Al tool in mapping tumour cells distribution and lymphocytic infiltration in histological tissues from transmissible cancers and its generalisability to 18 other species. To the best of our knowledge, this is the first effort to apply computational pathology algorithms to transmissible cancers and pan-species pathology beyond mammals, thereby decoding the composition of cells in tumours across species. Our approach aims to pave the way for pan-species comparative pathology and contribute to understanding the emergence and prevalence of cancer in nature.

\section{Results}

\section{Collection and quality control for veterinary histology samples}

Ten hematoxylin and eosin (H\&E)-stained tumour samples from 3 individuals with Tasmanian devil facial tumour disease 1 and 2 (DFT1 and DFT2) and 6 with canine transmissible venereal tumour (CTVT) were collected and digitalised from the Transmissible Cancers Group, University of Cambridge. Of these, 7 passed visual quality control for image analysis. One representative slide was chosen by the pathologists for each species considering scanning resolution and level of immune infiltration in the tumour microenvironment. In addition, H\&E samples from 18 species were selected from the Zoological Society of London's (ZSL) pathological archive and digitalised (classes Mammalia $=11$ species, Reptilia $=4$, Aves $=2$, and Amphibia $=1$ ). The neoplastic lesions were broadly categorised into five main tumour groups: round-cell $(n=4)$, epithelial $(n=9)$, mesenchymal $(n=4)$, neuroendocrine $(n=2)$ and sex-cord stromal $(n=1)$ tumours. A rich, pan-species digital pathology atlas was created, providing digital slide images, digitalisation and quality control protocols, and pathological annotations described below.

\section{Transferring Al technologies to non-human species}

A deep learning pipeline tailored for human lung cancer (predominantly lung adenocarcinoma, including lung squamous cell carcinoma ${ }^{33}$, Fig. $1 \mathrm{~A}$ ) was applied without modification to all 20 $\mathrm{H} \& \mathrm{E}$ samples. Briefly, this pipeline identifies the precise location of individual cells in each $\mathrm{H} \& \mathrm{E}$ and classifies them based on nuclear morphology in one of four cell types: tumour cells, lymphocytes, stromal cells (fibroblasts and endothelial cells) and 'other' cells (macrophages, pneumocytes and non-identifiable cells) (Fig. 1B-C). We evaluated the accuracy of the convolutional neural network (CNN) with 14,570 cancer, lymphocyte, and stromal single-cell annotations from two board-certified specialist veterinary pathologists ( $\mathrm{CP}$ and $\mathrm{KH})$. For each 
117 slide, we computed the algorithm's balanced single-cell classification accuracy (BCAcc, Table

118 1), as well as F1 score, precision, sensitivity and specificity (Figs S1-S2).

119 For evaluating the accuracy in classifying cells by the algorithm, we compared its predictions

120 against veterinary pathologists' annotations. The algorithm's average balanced accuracy across

121 cell classes showed a diverse range of variation between and within tumour groups (Figs. 2A,

122 S1-S2). Tumour types have the same overall accuracy for cell classification based on the

123 balanced classification accuracy values (LR test, overall BCAcc averaged across samples =

1240.81 ; LR test, $\left.X^{2}[3]=0.314, p=0.957\right)$. Moreover, despite the heterogeneous number of

125 annotations per tumour type (Fig. 2B), the balanced accuracy was not associated with the

126 number of annotations (Spearman's $\rho=0.088, p=0.71$ ) (Fig. 2B-C).

\section{Consistent accuracy across tumour types but higher in mammals}

129 Overall, the model's best performance was mainly in mammals (Fig. 3). In particular, the Al 130 algorithm achieves high accuracy in measuring immune response for the two transmissible 131 cancers (canine transmissible venereal tumour - CTVT, 0.94; Tasmanian devil facial tumour 132 disease- DFTD, 0.88). The canine transmissible venereal tumour (in Canis I. familiaris) exhibited 133 the best accuracy across all 20 species (overall precision $=0.98, \mathrm{~F} 1$ and BCAcc $=0.94$, Fig. 3).

134 Surprisingly, in the metastatic sarcoma in a snake (Gonyosoma oxycephalum), the CNN also 135 reached a high accuracy (Fig. 4A, overall precision $=0.89, \mathrm{~F} 1=0.89$ and $\mathrm{BCAcC}=0.91$ ).

136 In the 18 other vertebrate species (mammalia=11, reptilia=4, aves=2, and amphibia=1), 137 accuracy varies (0.57-0.94). The performance of cancer cells and lymphocyte classification, 138 measured as balanced accuracy, did not vary between tumour types (LR test, cancer cells: 139 median $=0.825, x^{2}[3]=1.358, p=0.715$; lymphocytes: median $=0.915, x^{2}[3]=0.308, p=$ 140 0.959). However, the classification accuracy of stromal cells differs between tumour types (LR 141 test, median $\left.=0.773, x^{2}[3]=10.308, p=0.016\right)$, with $p$-adjusted significant only for differences 142 between epithelial-round cell ( $z$-test, estimate $=-0.092, \mathrm{SE}=0.031, \mathrm{z}=-3.073, \mathrm{p}=0.018$ ) and 143 mesenchymal-round cell tumour types (estimate $=-0.121, \mathrm{SE}=0.039, z=-3.073, p=0.011$ ).

144 All other comparisons have a p-value higher than 0.05. Surprisingly, in both cases where we 145 reported significant differences, the balanced accuracy of stromal cells in round-cell tumour 146 types was higher than mesenchymal or epithelial tumour types. In our cohort, the round-cell 147 tumour types were present in the dog (Canis familiaris), the Tasmanian devil (Sarcophillus 148 harrisii), the pygmy goat (Capra hircus) and the ring-tailed coati (Nasua nasua). These results 149 show a high classification accuracy of the model consistent with expert pathologists' annotations 150 across tumour types for cancer cells and lymphocytes and slight variations in the case of 151 stromal cells.

\section{Species and cancer-specific challenges}

154 The detection of cancer cells presented more challenging classifications in lymphosarcoma from 155 the common goat (Capra hircus), the ring-tailed coati (Nasua nasua) and in lipoma from the 
dwarf crocodile (Osteolaemus tetraspis), which by their cell morphology and tissue architecture may be difficult to be classified by an algorithm trained with epithelial cells from human lung adenocarcinoma (Fig. 4B). These results suggest that the accuracy of computational pathology at single-cell resolution depends on the type of target cancer and its degree of differentiation from the training cancer type. Morphologically complex cancers that drastically change their morphological features or cancers with a high degree of similarity to the normal cells (e.g. lymphosarcoma) represent significant hurdles for transfer learning.

\section{Morphological preservation across species}

To explore the morphological similarity between human and non-human samples, which could explain the accuracy of the Al algorithm, we visualised the morphological space of $\sim 32 \mathrm{~K}$ cells annotated by expert pathologists using principal component analysis (Fig 5). The PCA analysis was used for dimension reduction (Fig 5) of the 27 features extracted by the Al algorithm at the individual cell level (Table S2). The first three PCA dimensions account for $84.1 \%$ of the morphological variance (Fig S3A). The first dimension explains $49.4 \%$ of the morphological variance, and the cell features with the highest contributions to that explained variance are associated with nucleus size (area, perimeter, diameter, radius, convex area) and maximum intensity in the colour channels (Fig S3B). These variables are positively correlated with the first dimension, with high importance to explaining individual cells' position in the morphological space (Fig S3C). The overlap of the volumes in PCA space suggests a high degree of morphological similarity between human and non-human cells (Table S3). For non-human lymphocytes, $84.55 \%$ of their morphological space intersects with the human lymphocyte morphospace. And for non-human tumour cells volume, which shows higher morphological variability, $86.49 \%$ of its volume is captured by human tumour cells' volume.

\section{Morphospace overlap as a new guidance metric}

To further dissect the relationship between the Al performance and morphological similarity across species, we developed a new metric, termed morphospace overlap, as the average of overlaps of cancer cell/lymphocyte morphological space between a species and humans. We found that the Al model's balanced accuracy is positively correlated with morphospace overlap (Pearson's correlation $=0.68, p=0.001$; Fig 5B), suggesting that the Al model performed better on species sharing higher morphological similarity with human cells. Species-specific analyses revealed further understanding of the model's performance. Among the tissues with higher balanced accuracy and high morphospace overlap are dog's CTVT (Fig 5C), Tasmanian devils' DFTD (Fig 5D) and snake's sarcoma (Fig 5E) (morphospace overlap (\%) = 82.6, 72.2, and 83.4, balanced accuracy $=0.94,0.88$, and 0.91 , respectively) and the goat's lymphosarcoma (Fig 5F) as one of the challenging cases, with smaller morphological overlap between its tumour cells and human's cells (morphospace overlap $(\%)=47.4$, balanced accuracy $=0.7$ ). Species with $>70 \%$ morphospace overlap had an average of $87.5 \%$ balanced accuracy (range $79-94 \%$ ), and species with $>80 \%$ morphospace overlap averaged $88 \%$ balanced accuracy (range $80-94 \%$ ). Thus, this new metric may be a useful tool for pathologists to determine the usability of our Al tool. 


\section{Discussion}

199 Comparative oncology pursues the understanding of cancer as a shared phenomenon among species. Here, we have explored the potential of Al through automated pathological image analysis to study cancer morphology and immune response across the tree of life. Previous studies have often been limited to a single species, with applications mainly focused on canine and mouse models (e.g., ${ }^{8,13,34}$ ). To the best of our knowledge, this is the first study of computational pathology that includes tumours from vertebrates beyond mammals, such as aves, reptiles and one amphibian. Although the algorithm was trained on human samples, it could distinguish three major cell types with remarkable accuracy in most of the species

(19/20 species reached an accuracy $\geq 70 \%$ and $12 / 20$ species $\geq 80 \%)$. Broadly, our comparative analysis revealed that regardless of species, morphological conservation across species dictates that cells can be detected and correctly classified by a human specimentrained $\mathrm{Al}$, fostering our endeavour to develop pan-species computational pathology.

Since the model was trained with human epithelial tumour samples, the specimens for testing include other tumour types such as mesenchymal, round cell and neuroendocrine that can have a greater variety of cell morphology, and such diversity of species, and tumour types and sites, likely underpins the wide range of accuracy (0.57-0.94) achieved. For example, in the case of the malignant spindle cell tumour (haemangiosarcoma in a lemur), the neoplastic endothelial cells have large, rounded nuclei, which may appear morphologically similar to that of epithelial cancer cells, as opposed to the elongated nuclei of normal endothelial cells (Fig. 4C). Similarly, for the chimpanzee (Pan troglodytes) with a spindle cell sarcoma, the neoplastic fibroblasts are hard to differentiate from reactive fibroblasts with a spindle shape (Fig. 4D). This is a challenge both for the automated analysis and manually by pathologists. Another challenging aspect is the immune compartment, which is highly variable among mammals, birds and reptiles ${ }^{35}$, imposing difficulties that seem complicated to pass with a generic algorithm. Moreover, this is amplified when evaluating cancer affecting the lymphatic tissue, such as lymphosarcoma in the coati ( $N$. nasua) and pygmy goat (C. hircus), where the white blood cell morphology is altered. Lymphosarcoma cells generally appear similar to normal lymphoid cells, resulting in narrow discriminability chances. In those cases, it may be appropriate to take alternative strategies such as re-train the model, test available models for lymphosarcoma (e.g., ${ }^{36}$ ), or develop a new model incorporating other tissue characteristics. To address this issue, we developed a new metric, named morphospace overlap, to guide pathologists who wish to apply the Al tools to their samples based on morphological similarity. veterinary domain may be significantly higher than previously thought. Medical treatment for animals has dramatically improved in veterinary clinics, zoological institutions and even wildlife veterinarians $^{37}$, leading to better options for diagnosing and treating cancer in animal patients ${ }^{23}$. Despite these significant advances in veterinary oncology ${ }^{38}$, there are significant constraints and limited availability of veterinary specialists ${ }^{39}$, and consequently, digital tools are not widely

237 used $^{24,25}$. Thus, computational pathology for different species and tumour types will bring 
tremendous advances for clinical veterinary care and comparative oncology research ${ }^{24,40}$. Many of the advantages are similar to those for human pathology, with the greatest benefits being accessibility to veterinary pathologists, time saved and increased diagnostic accuracy. Significant challenges remain. For instance, our study's low rate of samples passing quality control highlights a marked difference in sample management between veterinary and human cancer care. Therefore, the pan-species digital pathology atlas, protocols and guidelines for veterinary pathologists provided in this study represent a big step towards rational and efficient transfer of Al technologies to veterinary medicine.

Another potential impact of this study is to empower precision medicine for treating animal cancers. Accurate diagnosis and timely treatment could be critical in preserving endangered and threatened species that represent important breeding populations ${ }^{41}$. We demonstrated how the Al tool can be used to study lymphocytic infiltration in canine transmissible venereal tumours and Tasmanian devil facial tumours with high accuracy and spatial resolution (Fig. 1B-C). As a transmissible disease, the immune response at the organismal level may offer new alternatives to understand the spread of the disease at a population scale from an epidemiological perspective ${ }^{42,43}$. These tumours can colonise a new host by crossing the barriers of histocompatibility associated with the immune system and expressing immunosuppressive cytokines $^{44,45}$. The quantification and spatial detection of both tumour and immune cells can help study immune evasion and treatment in transmissible cancers, building on progress on understanding T cells immune infiltration in Tasmanian devils ${ }^{46}$ and immune regulation in dog's CTVT tumour regression ${ }^{47}$. Furthermore, a detailed study of the tumour microenvironment can guide new discoveries to understand the mechanisms behind sensitivity and resistance to standard treatments such as chemotherapy, ${ }^{4849}$. By enabling precision medicine we can advance towards a more personalised and integrative approach to veterinary care ${ }^{50}$.

Comparative oncology also brings tremendous benefits to human cancer research ${ }^{5,51,52}$. Our knowledge of cancer in wild animals is limited, and computational pathology can greatly expand research opportunities that compare cancer in the wild to managed populations, as well as comparisons with human cancer. Cross-species cancer comparisons may help address fundamental questions in cancer biology and evolution. This work revealed highly conserved morphology features across many species, particularly in epithelial and round-cell tumours, highlighting potential evolvability constraints for certain tumour types. The mismatch between species' evolutionary history and the conserved cellular morphological diversity raises new questions on the origin of cell morphological patterns; is morphological conservation fixed early in metazoan evolutionary history? Or is it the result of stabilising selection imposed by the extracellular matrix to meet homeostatic conditions ? $^{53,54}$ Addressing the conserved features and differences in tumour biology can lead to novel research, therapeutics and discoveries that one day could be translated into human and non-human clinical care ${ }^{37,55}$.

275 Limitations of this study include the limited availability of samples and annotations. It will be important to validate our findings on extended pan-species cohorts and advance our understanding of intratumor heterogeneity across different species and derive more controlled interspecies comparisons. With detailed multiplexing profiles, future attempts can shed more

279 light on immune compositions in the microenvironment. 
This work represents a step forward in incorporating machine learning in diagnostic investigations of natural and emerging diseases in animals, enhancing accuracy and sensitivity and complementing veterinary pathologists' capability in the decision-making process. Computational pathology can bring valuable opportunities for automated diagnosis, tumour grading, scoring, and precision medicine for animal cancers.

\section{Materials and Methods}

In total, $99 \mathrm{H} \& \mathrm{E}$ samples from 29 species were identified from the Zoological Society of London's (ZSL) pathological archive, derived from clinical or postmortem examinations of ZSL London Zoo's living collections (Table S1). Of these, 51 slides from 22 species passed quality control for image analysis, and 18 slides representing 18 species were selected by the pathologists for subsequent analyses. Exclusion criteria were the lack of tumour components and the presence of high amounts of melanin/pigments in the tissue samples hindering the correct identification of individual cells. Samples were either obtained through tissue biopsies from surgery or routine postmortem examinations from animals that were i) examined directly after euthanasia or ii) stored at 4 degrees Celsius and examined within two days of death. A suspect tumour was removed, fixed in $10 \%$ buffered formalin solution and trimmed before being sent to external institutions (IZVG Pathology and Finn Pathologists) for histopathological processing, where they were subsequently embedded in paraffin blocks, sectioned and stained with H\&E for analysis. Additionally, two samples were provided by the Transmissible Cancer Group, University of Cambridge, as previously reported in the following studies: Canis familiaris ${ }^{56}$ and Sarcophilus harrisii ${ }^{9}$.

303 NanoZoomer digital pathology system v.3.1.7 (Hamamatsu) at 40X (228 nm/pixel resolution).

304 The entire deep learning-based single-cell analysis pipeline described in ${ }^{33}$ was implemented.

305 This pipeline was designed and developed for human lung tumour specimens. Briefly, all 20

306 whole-section images were first down-scaled to $\times 20$ and then tiled into $2000 \times 2000$ images

307 for subsequent three-stage analysis. Firstly, all viable H\&E tissue areas are segmented.

308 Secondly, within the segmented tissue image, a spatially-constrained convolutional neural

309 network predicts for each pixel the probability that it belongs to the centre of a nucleus; cell

310 nuclei were then detected from the probability map obtained from the deep network. Lastly,

311 each identified cell was classified using a neighbouring ensemble predictor coupled with a

312 spatially constrained convolutional neural network. There were four cell classes: cancer

313 (malignant epithelial) cells, lymphocytes (including plasma cells), noninflammatory stromal cells

314 (fibroblasts and endothelial cells) and an 'other' cell type that included non-identifiable cells, less

315 abundant cells such as macrophages and chondrocytes and 'normal' pneumocytes and

316 bronchial epithelial cells. 
317 Because the evaluation of the 'other' cell type class would be less mean, given the context of 318 this study, we focused on the three main classes. Two board-certified specialist veterinary

319 pathologists (CP and $\mathrm{KH}$ ) annotated 14,570 cancer, lymphocyte and stromal single-cell

320 annotations on raw whole-section images.

321 Features extraction at the cell level was done with two steps: a pre-trained MicroNet model ${ }^{57}$ on 322 lung $\mathrm{H} \&$ Es to segment all cells, followed by automatic extraction of morphological

323 measurements for the set of properties from each cell's mask. This allowed the extraction of 27

324 features for immune and tumour cells annotated by pathologists in the human and non-human

325 slides (MATLAB function 'regionprops' with additional modifications as defined in Table S2).

326 Annotated cells were mapped to the segmented cell centroid with a strict threshold of 4 pixels $(<$

$3272 \mu \mathrm{m}$, which is less than $1 / 3$ of a lymphocyte cell), and were visually assessed to confirm correct

328 mapping. Dimension reduction was performed using principal component analysis. Then, we

329 selected the first three dimensions of the PCA, enabling us to build a morphological volume for

330 each cell class. We computed morphological space overlap using the R package 'dynRB', which

331 calculates overlap based on the product of overlap at each dimension, the mean overlap across

332 dimensions, or the geometrical mean across the PCA dimensions. We focus on quantifying the

333 percentage of animal cells' morphological space that is covered by human cells' morphological

334 space.

335 The algorithms' performance for detecting and classifying cells across all species was evaluated 336 directly against the ground truth provided by pathologists' annotations. Individual class accuracy 337 statistics were calculated using the R function 'confusionMatrix' from the R package 'caret'. To 338 analyse the variability in the classification balanced accuracy values, BCAcc, across tumour or 339 cell types, we fit a generalised linear model considering a beta distribution (logit link function) for 340 continuous values between 0 and 1 ( $R$ package betareg). We computed likelihood ratio tests ( $R$ 341 package Imtest) to evaluate if the distribution of balances accuracy between tumour types 342 comes from the same $X^{2}$ distribution. When the $X^{2}$ test was significant $(p<0.05)$, we applied 343 multiple comparisons correcting $p$-values using Tukey's procedures (R package emmeans). All 344 the statistical tests were performed in $\mathrm{R}$ (version 4.0.3) and corresponding $\mathrm{R}$ codes are 345 available at https://github.com/simonpcastillo/PanSpeciesHistology. 
Tables

Table 1 Summary of overall balanced classification accuracy (BCAcc) by species. Balanced accuracy is computed as the average of sensitivity and specificity, 'overall' refers to the average of cancer, stromal and lymphocyte cells.

\begin{tabular}{|c|c|c|c|c|c|c|c|}
\hline Code & Common name & Species & Diagnosis & Neoplasia site & Tumour type & Annotations & BCACC \\
\hline BITARI & Puff adder & Bitis arietans & Carcinoma & Pancreas & Epithelial & 336 & 0.88 \\
\hline CANFAM & Dog & Canis familiaris & $\begin{array}{l}\text { Canine transmissible } \\
\text { venereal tumor }\end{array}$ & Intra vaginal & Round-cell & 629 & 0.94 \\
\hline CAPHIR & $\begin{array}{l}\text { West African pygmy } \\
\text { goat }\end{array}$ & Capra hircus & Lymphosarcoma & Forestomach & Round-cell & 965 & 0.70 \\
\hline CRAHEA & Panay cloudrunner & Crateromys heaneyi & Hepatocellular carcinoma & Liver & Epithelial & 730 & 0.89 \\
\hline CYACYA & $\begin{array}{l}\text { Red-legged } \\
\text { honeycreeper }\end{array}$ & Cyanerpes cyaneus & Sertoli cell tumor & Testis & $\begin{array}{l}\text { Sex-cord } \\
\text { stromal }\end{array}$ & 762 & 0.86 \\
\hline DASBYR & Kowari & Dasyuroides byrnie & Squamous cell carcinoma & Mouth & Epithelial & 462 & 0.74 \\
\hline GALMOH & Greater bushbaby & Galago moholi & Squamous cell carcinoma & Skin & Epithelial & 684 & 0.79 \\
\hline GONOXY & Redtailed ratsnake & $\begin{array}{l}\text { Gonyosoma } \\
\text { oxycephala }\end{array}$ & $\begin{array}{l}\text { Metastatic anaplastic } \\
\text { sarcoma }\end{array}$ & Multiple & Mesenchymal & 526 & 0.91 \\
\hline LEMCAT & Ring-tailed lemur & Lemur catta & Haemangiosarcoma & Kidney & Mesenchymal & 1049 & 0.79 \\
\hline LEOCHR & $\begin{array}{l}\text { Golden-headed Lion } \\
\text { Tamarin }\end{array}$ & $\begin{array}{l}\text { Leontopithecus } \\
\text { chrysomelas }\end{array}$ & Adenoma & Pituitary & Epithelial & 601 & 0.94 \\
\hline LEPFAL & Mountain chicken frog & Leptodactylus fallax & Adenocarcinoma & Celomic cavity & Epithelial & 740 & 0.81 \\
\hline MELURS & Sri Lankan sloth bear & $\begin{array}{l}\text { Melursus ursinus } \\
\text { inornatus }\end{array}$ & Pheochromocytoma & Adrenal & Neuroendocrine & 959 & 0.88 \\
\hline MUSPUT & Domestic polecat & Mustela putorius furo & Sebaceous epithelioma & Skin & Epithelial & 702 & 0.88 \\
\hline
\end{tabular}




\begin{tabular}{|l|l|l|l|l|l|l|}
\hline NASNAS & Brown-nosed coati & Nasua nasua & Lymphosarcoma & Multiple & Round-cell & 520 \\
\hline OSTTET & $\begin{array}{l}\text { West African dwarf } \\
\text { crocodile }\end{array}$ & $\begin{array}{l}\text { Osteolaemus tetraspis } \\
\text { tetraspis }\end{array}$ & Lipoma & Liver & Neuroendocrine & 1142 \\
\hline PANTRO & Chimpanzee & Pan troglodytes & Spindle cell tumor & Palate & Mesenchymal & 866 \\
\hline SARHAR & Tasmanian devil & Sarcophilus harrisii & Devil facial tumor 1 (DFT1) & Hard palate near left side & Round-cell & 484 \\
\hline SPHHUM & Humbolt penguin & Spheniscus humboldti & Renal cell adenoma & Kidney & 0.75 \\
\hline SUSBAR & Bearded Pig & Sus barbatus & Adenocarcinoma & Uterus & 0.88 \\
\hline VARPRA & Emerald monitor & Varanus prasinus & Spindle cell sarcoma & Multiple & 452 & 0.72 \\
\hline
\end{tabular}




\section{Figures}

A

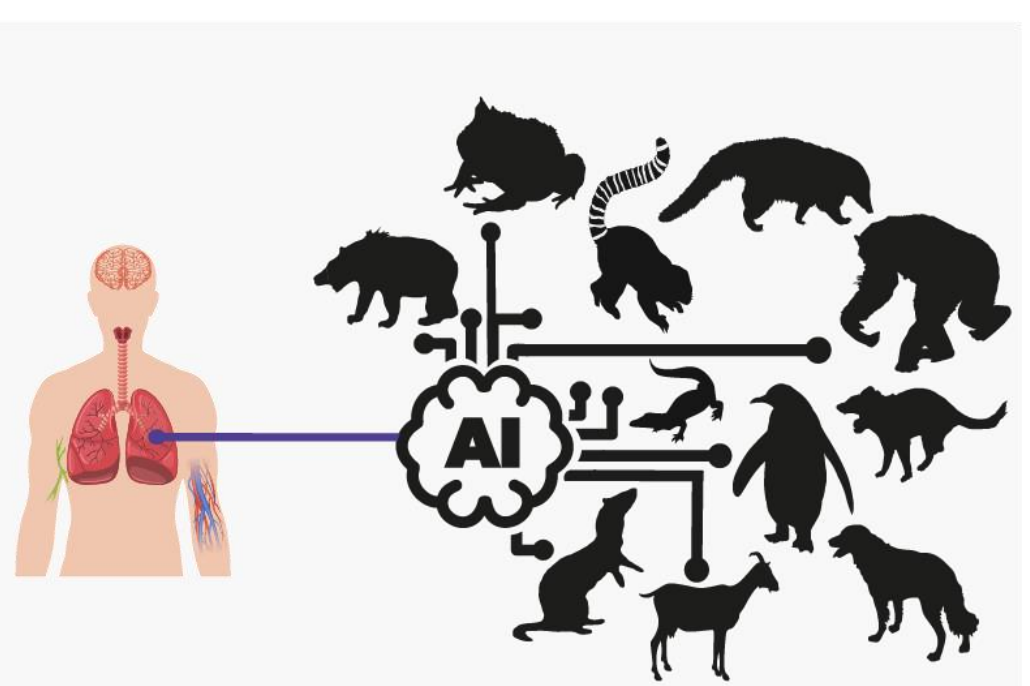

B H\&E tissue section

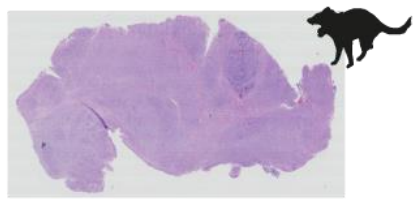

Tissue segmentation

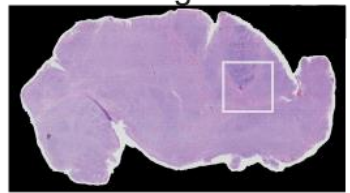

Cell detection and classification

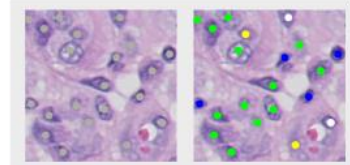

- Cancer Stromal • Lymphocyte o Other
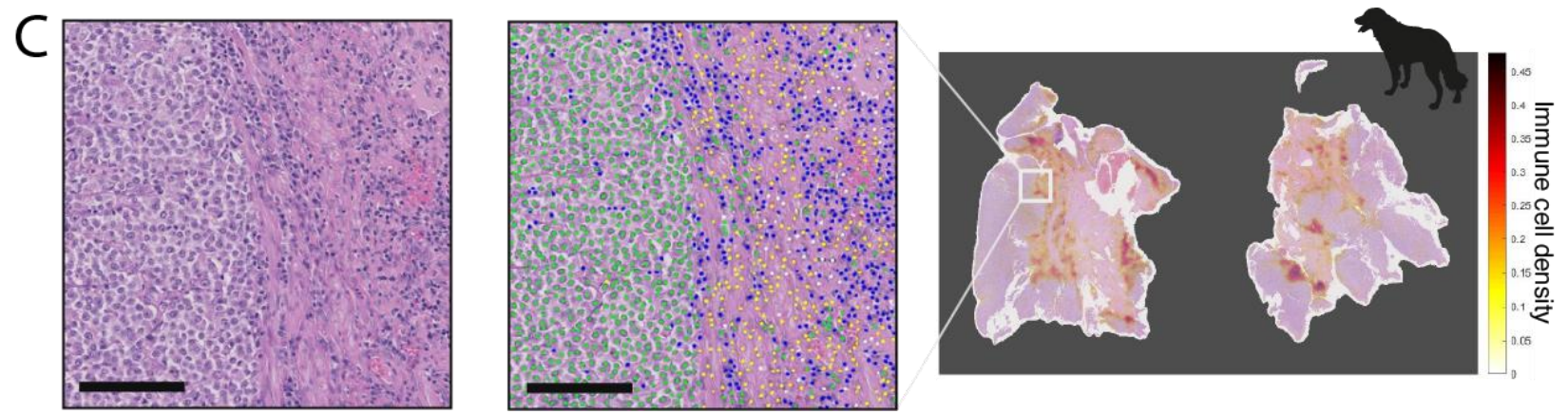

Figure 1 Pan-species computational pathology. (A) Transfer learning of cell identification from human lung to pan-species tumour pathology. (B) Overview of the H\&E single-cell analysis pipeline illustrated from a Tasmanian devil's (SARHAR) facial tumour. This Al pipeline ${ }^{33}$ first segments the viable tissue area, then detects and classifies all cells into cancer, stromal, lymphocyte and others. For more details, see Methods. (C) The same pipeline is implemented to spatially profile the immune microenvironment in a dog's (CANFAM) transmissible venereal tumour. Scale bar, $250 \mu \mathrm{m}$. Cell colours are denoted as four training classes, green: cancer (malignant epithelial) cells; blue: lymphocytes (including plasma cells); yellow: noninflammatory stromal cells (fibroblasts and endothelial cells); white: 'other' cell class that included nonidentifiable cells, less abundant cells such as macrophages and chondrocytes and 'normal' pneumocytes. 
A.

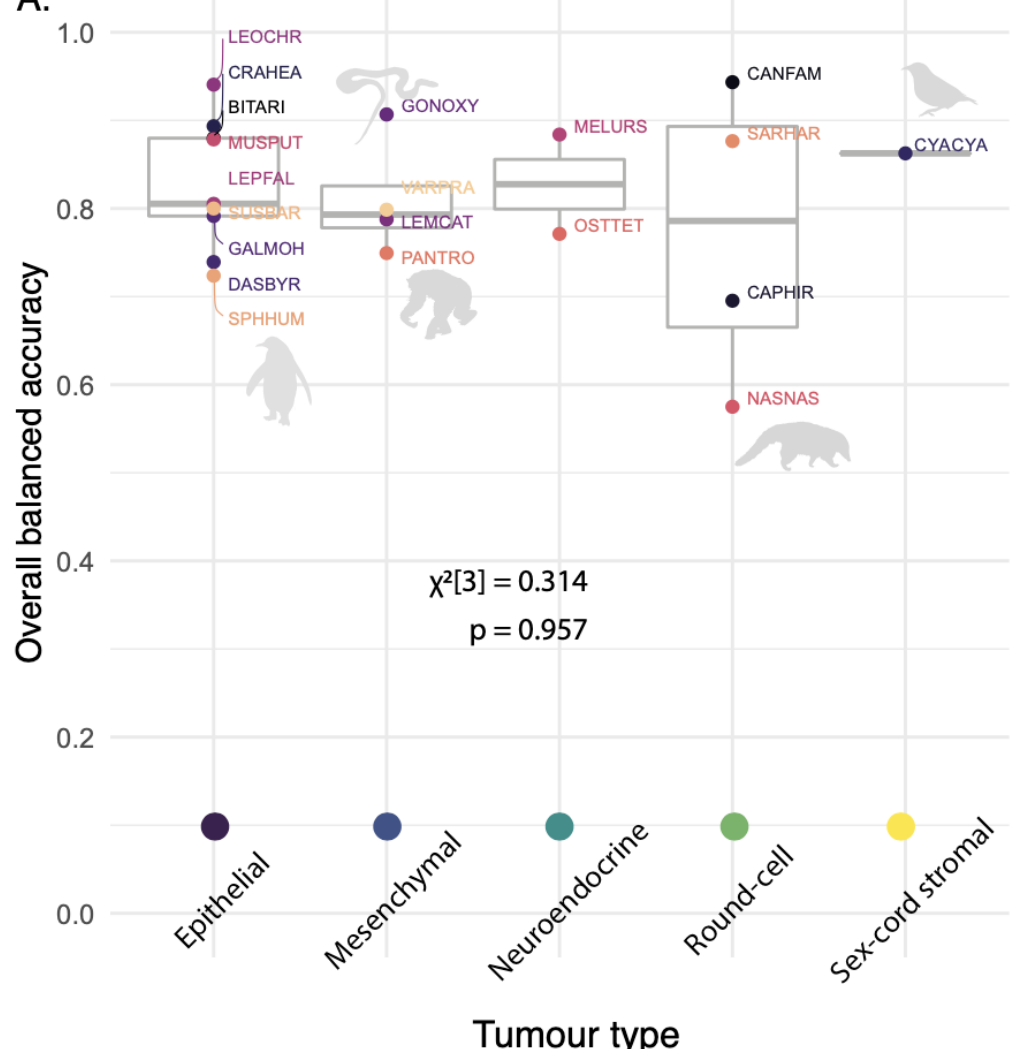

B.

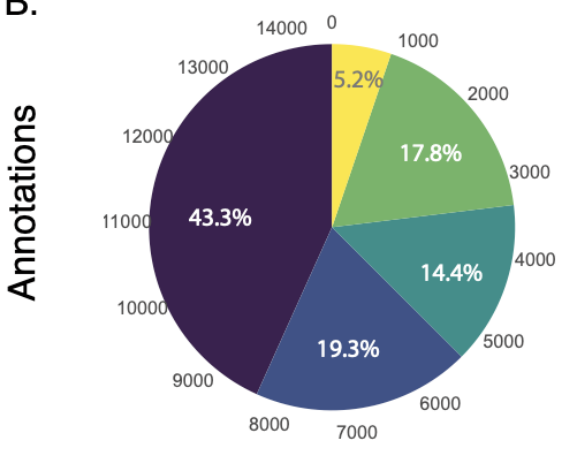

C.

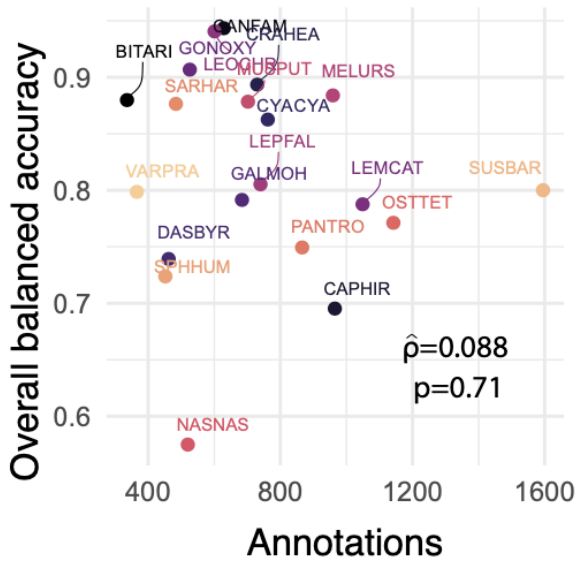

Figure 2 Al single-cell prediction comparison across tumour types. Balanced accuracy is computed as the average of sensitivity and specificity, 'overall' refers to the average of cancer, stromal and lymphocyte cells. (A) Pan-species overall balanced accuracy grouped by tumour type. (B) Distribution of the number of annotations by tumour type (colours correspond to tumour type in A). (C) Relationship between the number of annotations and the overall balanced accuracy for each species using Spearman's correlation. Species in (A) and (C) are labelled with their codes, for more species information, see Table 1. 
bioRxiv preprint doi: https://doi.org/10.1101/2022 03.05.482261; this version posted March 7, 2022. The copyright holder for this preprint (which was not certified by peer review) is the author/funder, who has granted bioRxiv a license to display the preprint in perpetuity. It is made available under aCC-BY-NC-ND 4.0 International license.

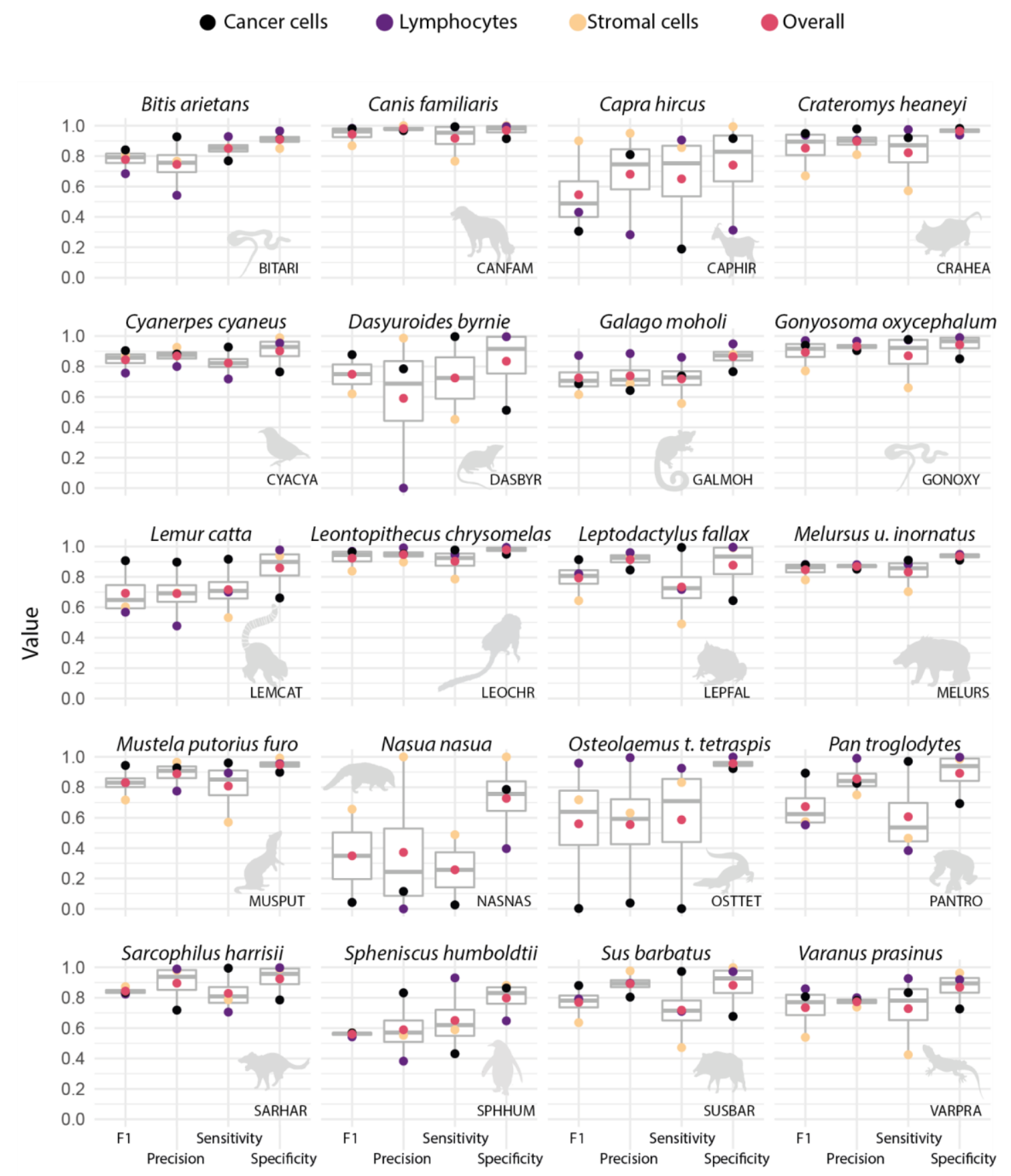

Metric

Figure 3 Al prediction variability for inter and intra- species tumour microenvironment cells. For each species, four metrics were evaluated including F1, precision, sensitivity and specificity (as labelled on the bottom $x$-axis) for the prediction accuracy of cancer, lymphocyte and stromal cells as well as their average shown as 'overall' (as denoted with colours on the top $\mathrm{x}$-axis). For species codes, see Table 1. 

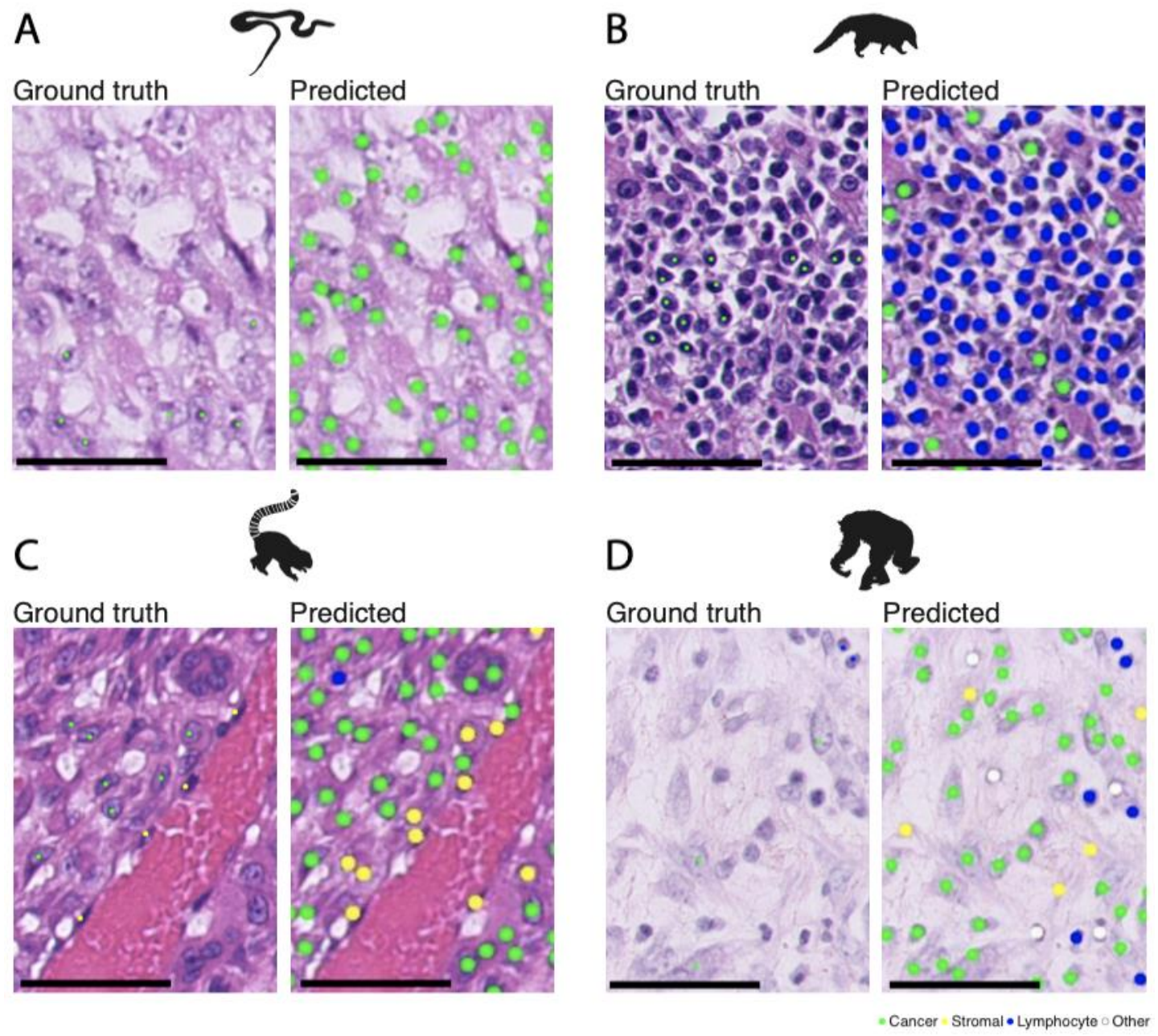

Figure 4 Strengths and pitfalls of current methods. Each H\&E example is shown as a raw image with expert pathology annotations on some cells (left) and Al cell identification (right). Scale bar, $100 \mu \mathrm{m}$. Cell colours are denoted as four training classes, green: cancer (malignant epithelial) cells; blue: lymphocytes (including plasma cells); yellow: noninflammatory stromal cells (fibroblasts and endothelial cells); white: 'other' cell class that included nonidentifiable cells, less abundant cells such as macrophages and chondrocytes and 'normal' pneumocytes. (A) Correct identification of cancer cells from a mesenchymal tumour (metastatic anaplastic sarcoma) in a snake (GONOXY). (B) A challenging brown-nosed coati (NASNAS) case was diagnosed with a round-cell tumour (lymphosarcoma) where the cancer cell morphology is difficult to be recognised by an algorithm trained with epithelial cells from human lung cancer. (C) A malignant spindle cell tumour from a ring-tailed lemur (LEMCAT) with a haemangiosarcoma disease, as shown, the neoplastic endothelial cells have large rounded nuclei, which may appear morphologically similar to epithelial cancer cells, as opposed to the AI model's own normal -stromal- endothelial cells. However, the model successfully distinguished the majority of neoplastic from stromal cells. Further complexity is in the occurrence of epithelioid haemangiosarcoma where the cells of origin are endothelial cells but they actually become epithelial-like. (D) In the case of a chimpanzee (PANTRO) with a spindle cell sarcoma, the neoplastic fibroblasts are harder to differentiate from reactive fibroblasts. 

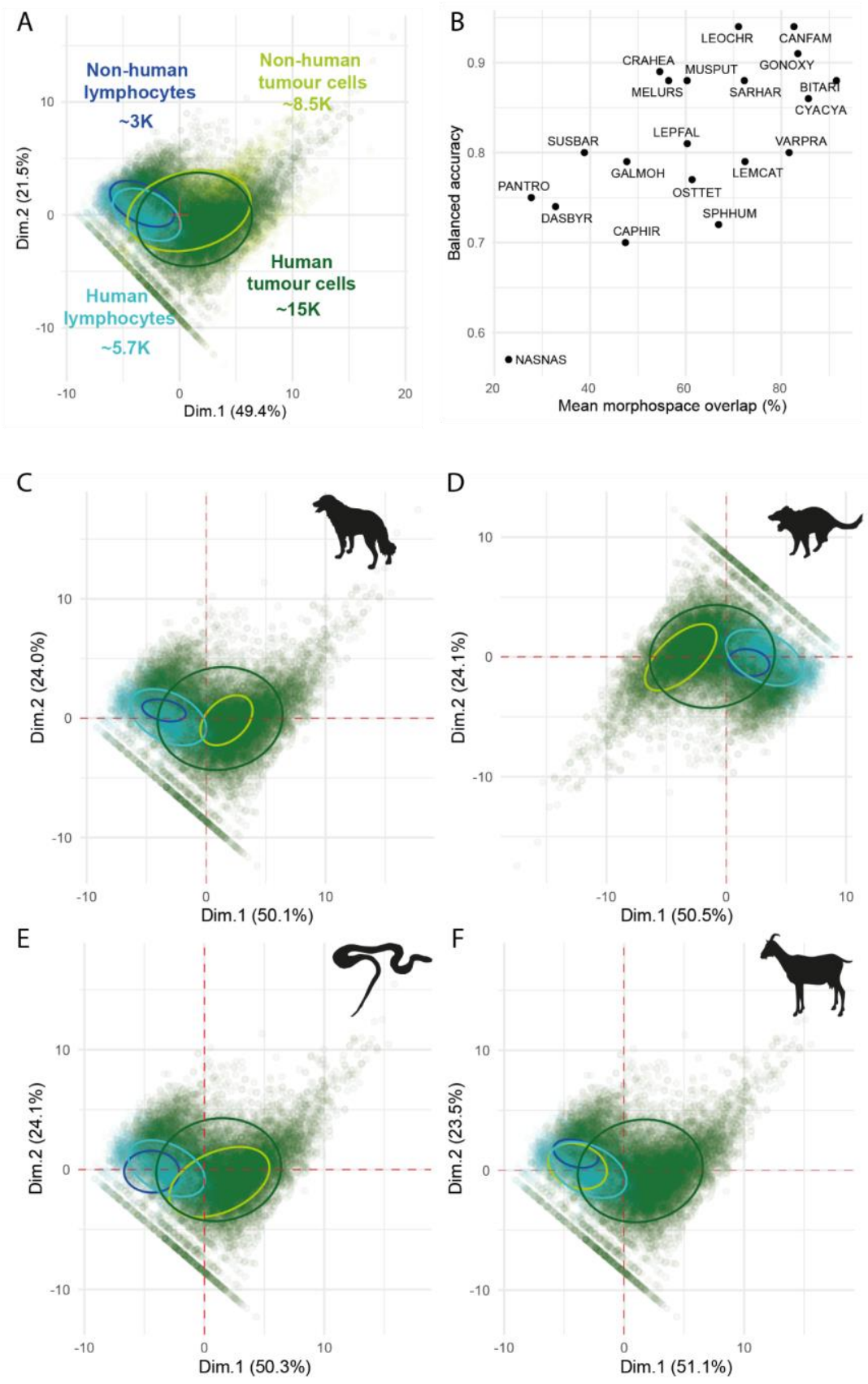

Figure 5 Overlap across the morphological space. (A) Overall high overlap between human and non-human cell morphologies across two dimensions of the principal component analysis, and their explained variances, of the morphological space made by $\sim 31 \mathrm{~K}$ cells annotated by pathologists. (B) the mean morphospace overlap across animal tumour cells and lymphocytes correlates with the model's balanced accuracy. (C-F) Species-specific morphological space overlap with human morphospace; (C) Canis I. familiaris (CANFAM), (D) Sarcophilus harrisii (SARHAR), (E) Gonyosoma oxycephala (GONOXY) and (F) Capra hircus (CAPHIR). Ellipses denote $95 \%$ of the distribution. 


\section{References}

1. Aktipis, C. A. et al. Cancer across the tree of life: cooperation and cheating in multicellularity. Phil. Trans. R. Soc. B 370, 20140219 (2015).

2. Kitsoulis, C. V., Baxevanis, A. D. \& Abatzopoulos, T. J. The occurrence of cancer in vertebrates: a mini review. J of Biol Res-Thessaloniki 27, 9 (2020).

3. Aktipis, C. A. \& Nesse, R. M. Evolutionary foundations for cancer biology. Evol Appl 6, 144-159 (2013).

4. Hughes, K. Comparative mammary gland postnatal development and tumourigenesis in the sheep, cow, cat and rabbit: Exploring the menagerie. Seminars in Cell \& Developmental Biology 114, 186-195 (2021).

5. Abegglen, L. M. et al. Potential Mechanisms for Cancer Resistance in Elephants and Comparative Cellular Response to DNA Damage in Humans. JAMA 314, 1850 1860 (2015).

6. Sulak, M. et al. TP53 copy number expansion is associated with the evolution of increased body size and an enhanced DNA damage response in elephants. eLife 5, e11994 (2016).

7. Shao, Y. W. et al. Cross-species genomics identifies DLG2 as a tumor suppressor in osteosarcoma. Oncogene 38, 291-298 (2019).

8. Wong, K. et al. Cross-species genomic landscape comparison of human mucosal melanoma with canine oral and equine melanoma. Nature Communications 10, 353 (2019).

9. Stammnitz, M. R. et al. The Origins and Vulnerabilities of Two Transmissible Cancers in Tasmanian Devils. Cancer Cell 33, 607-619.e15 (2018).

10. Murchison, E. P. Clonally transmissible cancers in dogs and Tasmanian devils. Oncogene 27, S19-S30 (2008).

11. Dujon, A. M. et al. Transmissible Cancers in an Evolutionary Perspective. iScience 23, 101269 (2020).

12. Pi Castro, D. et al. Expression of FOXP3 in Canine Gliomas: Immunohistochemical Study of Tumor-Infiltrating Regulatory Lymphocytes. Journal of Neuropathology \& Experimental Neurology 79, 184-193 (2020).

13. Aubreville, M. et al. A completely annotated whole slide image dataset of canine breast cancer to aid human breast cancer research. Scientific Data 7, 417 (2020).

14. Gardner, H. L., Fenger, J. M. \& London, C. A. Dogs as a Model for Cancer. Annual Review of Animal Biosciences 4, 199-222 (2016).

15. Pesavento, P. A., Agnew, D., Keel, M. K. \& Woolard, K. D. Cancer in wildlife: patterns of emergence. Nat Rev Cancer 18, 646-661 (2018).

16. Browning, H. M., Gulland, F. M. D., Hammond, J. A., Colegrove, K. M. \& Hall, A. J. Common cancer in a wild animal: the California sea lion (Zalophus californianus) as an emerging model for carcinogenesis. Philos Trans R Soc Lond B Biol Sci 370, (2015). 
17. Chang, P. H. et al. Spontaneous neoplasms in zoo mammals, birds, and reptiles in Taiwan - A 10-year survey. Animal Biology 62, 95-110 (2012).

18. Madsen, T. et al. Cancer Prevalence and Etiology in Wild and Captive Animals. Ecology and Evolution of Cancer 11-46 (2017) doi:10.1016/B978-0-12-8043103.00002-8.

19. Boddy, A. M. et al. Lifetime cancer prevalence and life history traits in mammals. Evolution, Medicine, and Public Health 2020, 187-195 (2020).

20. Junginger, J. et al. Pathology in Captive Wild Felids at German Zoological Gardens. PLOS ONE 10, e0130573 (2015).

21. McAloose, D. \& Newton, A. L. Wildife cancer: a conservation perspective. Nat Rev Cancer 9, 517-526 (2009).

22. Tuia, D. et al. Perspectives in machine learning for wildlife conservation. Nat Commun 13, 792 (2022).

23. Boddy, A. M., Harrison, T. M. \& Abegglen, L. M. Comparative Oncology: New Insights into an Ancient Disease. iScience 23, 101373 (2020).

24. Bertram, C. A. \& Klopfleisch, R. The Pathologist 2.0: An Update on Digital Pathology in Veterinary Medicine. Vet Pathol 54, 756-766 (2017).

25. Zuraw, A. \& Aeffner, F. Whole-slide imaging, tissue image analysis, and artificial intelligence in veterinary pathology: An updated introduction and review. Vet Pathol 59, 6-25 (2022).

26. Hoenerhoff, M. J., Meyerholz, D. K., Brayton, C. \& Beck, A. P. Challenges and Opportunities for the Veterinary Pathologist in Biomedical Research. Vet Pathol 58, 258-265 (2021).

27. Meuten, D. J. et al. International Guidelines for Veterinary Tumor Pathology: A Call to Action. Vet Pathol 58, 766-794 (2021).

28. Ezanno, P. et al. Research perspectives on animal health in the era of artificial intelligence. Vet Res 52, 40 (2021).

29. Aubreville, M. et al. Deep learning algorithms out-perform veterinary pathologists in detecting the mitotically most active tumor region. Scientific Reports 10, 16447 (2020).

30. Nagy, D. et al. Developing ovine mammary terminal duct lobular units have a dynamic mucosal and stromal immune microenvironment. Commun Biol 4, 993 (2021).

31. Awaysheh, A. et al. Evaluation of supervised machine-learning algorithms to distinguish between inflammatory bowel disease and alimentary lymphoma in cats. $J$ VET Diagn Invest 28, 679-687 (2016).

32. Mattoon, J. S. \& Bryan, J. N. The future of imaging in veterinary oncology: Learning from human medicine. The Veterinary Journal 197, 541-552 (2013).

33. AbdulJabbar, K. et al. Geospatial immune variability illuminates differential evolution of lung adenocarcinoma. Nature Medicine 26, 1054-1062 (2020). 
34. Elyada, E. et al. Cross-Species Single-Cell Analysis of Pancreatic Ductal Adenocarcinoma Reveals Antigen-Presenting Cancer-Associated Fibroblasts. Cancer Discov 9, 1102-1123 (2019).

35. Montali, R. J. Comparative pathology of inflammation in the higher vertebrates (reptiles, birds and mammals). Journal of Comparative Pathology 99, 1-26 (1988).

36. Syrykh, C. et al. Accurate diagnosis of lymphoma on whole-slide histopathology images using deep learning. npj Digital Medicine 3, 1-8 (2020).

37. Mestrinho, L. A. \& Santos, R. R. Translational oncotargets for immunotherapy: From pet dogs to humans. Advanced Drug Delivery Reviews 172, 296-313 (2021).

38. Dobson, J. M. Significant advances in veterinary oncology - 60 years on. Journal of Small Animal Practice 60, 711-722 (2019).

39. Gyles, C. Meeting demands in specialist training — whose responsibility? Can Vet $J$ 50, 687-690 (2009).

40. Riccardo, F., Aurisicchio, L., Impellizeri, J. A. \& Cavallo, F. The importance of comparative oncology in translational medicine. Cancer Immunol Immunother 64, 137-148 (2015).

41. McCallum, H. Tasmanian devil facial tumour disease: lessons for conservation biology. Trends in Ecology \& Evolution 23, 631-637 (2008).

42. Ujvari, B., Gatenby, R. A. \& Thomas, F. The evolutionary ecology of transmissible cancers. Infection, Genetics and Evolution 39, 293-303 (2016).

43. Jones, E. A., Cheng, Y. \& Belov, K. The origin, dynamics, and molecular evolution of transmissible cancers. AGG 5, 317-326 (2015).

44. Patchett, A. \& Woods, G. Targeting transmissible cancers in animals. Science 365 , 438-440 (2019).

45. Siddle, H. V. \& Kaufman, J. Immunology of naturally transmissible tumours. Immunology 144, 11-20 (2015).

46. Pye, R. et al. Demonstration of immune responses against devil facial tumour disease in wild Tasmanian devils. Biology Letters 12, 20160553 (2016).

47. Frampton, D. et al. Molecular Signatures of Regression of the Canine Transmissible Venereal Tumor. Cancer Cell 33, 620-633.e6 (2018).

48. Hui, L. \& Chen, Y. Tumor microenvironment: Sanctuary of the devil. Cancer Letters 368, 7-13 (2015).

49. Klopfleisch, R., Kohn, B. \& Gruber, A. D. Mechanisms of tumour resistance against chemotherapeutic agents in veterinary oncology. The Veterinary Journal 207, 63-72 (2016).

50. Klopfleisch, R. Personalised medicine in veterinary oncology: One to cure just one. The Veterinary Journal 205, 128-135 (2015).

51. Nunney, L., Maley, C. C., Breen, M., Hochberg, M. E. \& Schiffman, J. D. Peto's paradox and the promise of comparative oncology. Philosophical Transactions of the Royal Society B: Biological Sciences 370, 20140177 (2015). 
52. Schiffman, J. D. \& Breen, M. Comparative oncology: what dogs and other species can teach us about humans with cancer. Philosophical Transactions of the Royal Society B: Biological Sciences 370, 20140231 (2015).

53. Bissell, M. J. \& Barcellos-Hoff, M. H. The Influence of Extracellular Matrix on Gene Expression: Is Structure the Message? Journal of Cell Science 1987, 327-343 (1987).

54. Watt, F. M. The extracellular matrix and cell shape. Trends in Biochemical Sciences 11, 482-485 (1986).

55. Klingemann, H. Immunotherapy for Dogs: Running Behind Humans. Front Immunol 9, 133 (2018).

56. Strakova, A. et al. Recurrent horizontal transfer identifies mitochondrial positive selection in a transmissible cancer. Nat Commun 11, 3059 (2020).

57. Raza, S. E. A. et al. Micro-Net: A unified model for segmentation of various objects in microscopy images. Medical Image Analysis 52, 160-173 (2019). 


\section{Acknowledgements:}

The authors wish to thank Edmund Flach from the Zoological Society of London, as well as external pathologists Mark Stidworthy, Daniella Denk, Cheryl Sangster, and Ann Pocknell. LMA acknowledges support from the Department of Pediatrics Research Enterprise (University of Utah). Figure icons were taken from phylopic.org (CC BY 3.0), thanks to Sarah Werning, Rebecca Groom, T. Michael Keesey and Tony Hisgett.

\section{Funding:}

The Arizona Cancer Evolution Center, University of Arizona, USA.

National Institutes of Health grant U54 CA217376 (YY, AMB, LMA, TAG)

National Institutes of Health grant R01 CA185138 (YY)

Cancer Research UK Career Establishment Award C45982/A21808 (YY)

Cancer Research UK Early Detection Program Award C9203/A28770 (YY)

Cancer Research UK Sarcoma Accelerator C56167/A29363 (YY)

Cancer Research UK Brain tumour Award C25858/A28592 (YY, SPC)

Rosetrees Trust A2714 (YY)

Children's Cancer and Leukaemia Group CCLGA201906 (YY)

The Royal Marsden Hospital, the ICR National Institute of Health Research Biomedical Research Centre (YY).

Department of Pediatrics Research Enterprise, University of Utah (LMA)

\section{Author contributions:}

Conceptualization: KA, SPC, EPM, TAG, CP, YY; Methodology: KA, SPC, CP, KH, HD, SS, EF; Investigation: KA, SPC, CP, YY; Writing: SPC, KA, YY, AMB, LMA, CP, YY, with input from all authors.

\section{Competing interests:}

The funders had no role in the design of the study; the collection, analysis, or interpretation of the data; the writing of the manuscript; or the decision to submit the manuscript for publication. 
Y.Y. has received speakers bureau honoraria from Roche and consulted for Merck and Co Inc. L.M.A. is a share-holder and consultant to PEEL Therapeutics, Inc.

\section{Data and materials availability:}

The deep-learning pipeline for digital pathology image analysis is previously available for noncommercial research purposes at https://github.com/galid7/compath. All code used for statistical analyses of image data and morphospace overlap test tool was developed in R (v.4.0.3) and it is available at https://github.com/simonpcastillo/PanSpeciesHistology. A rich, pan-species digital pathology atlas will be made publicly available upon publication, providing pan-species digital slide images, slide digitalisation and quality control protocols, and pathological annotations of 14,570 single-cell annotations across 20 species. 
bioRxiv preprint doi: https://doi.org/10.1101/2022.03.05.482261; this version posted March 7, 2022. The copyright holder for this preprint (which was not certified by peer review) is the author/funder, who has granted bioRxiv a license to display the preprint in perpetuity. It is made available under aCC-BY-NC-ND 4.0 International license.

\section{Supplementary}

A. Cancer cells

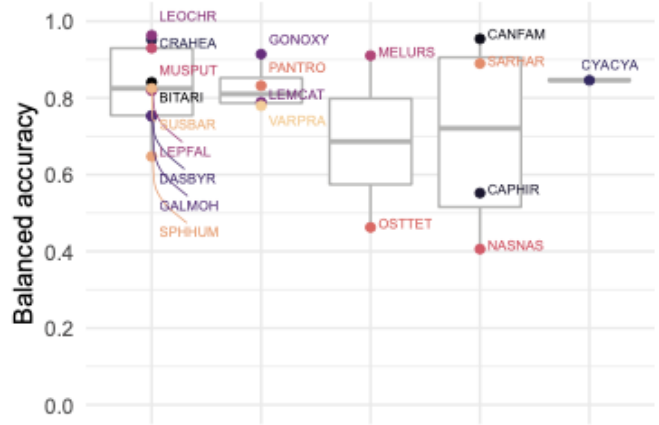

B. Lymphocytes

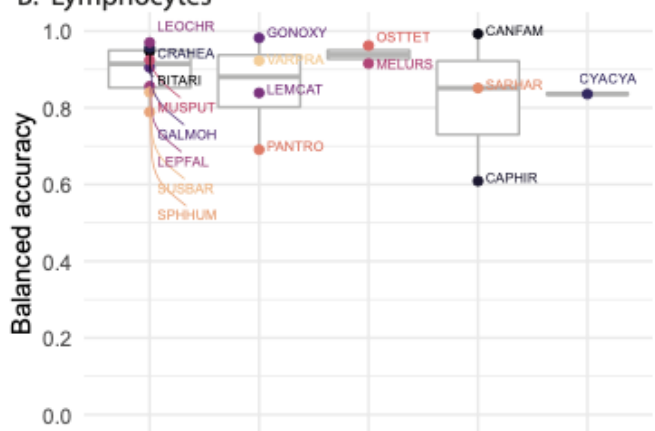

C. Stromal cells

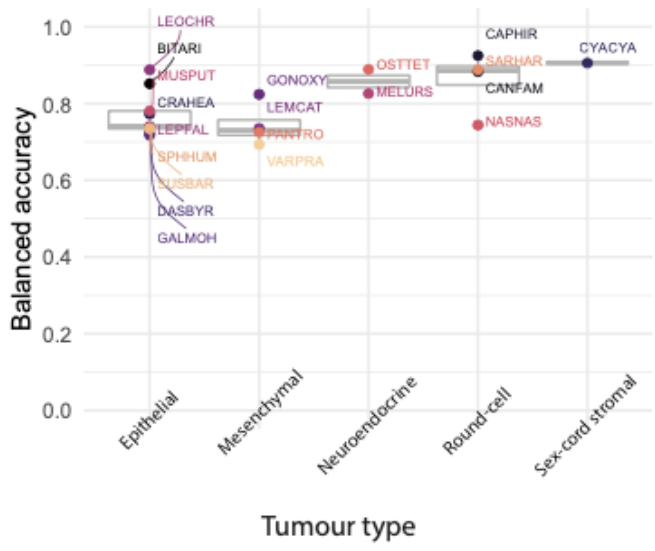

Supplementary Figure 1 Extended Al single-cell prediction comparison across tumour types. Balanced accuracy is computed as the average of sensitivity and specificity for $(A)$ cancer, (B) stromal and (C) lymphocyte cells for all species. Species are grouped according to their tumour type and are labelled with their codes, for more species information, see Table 1. 

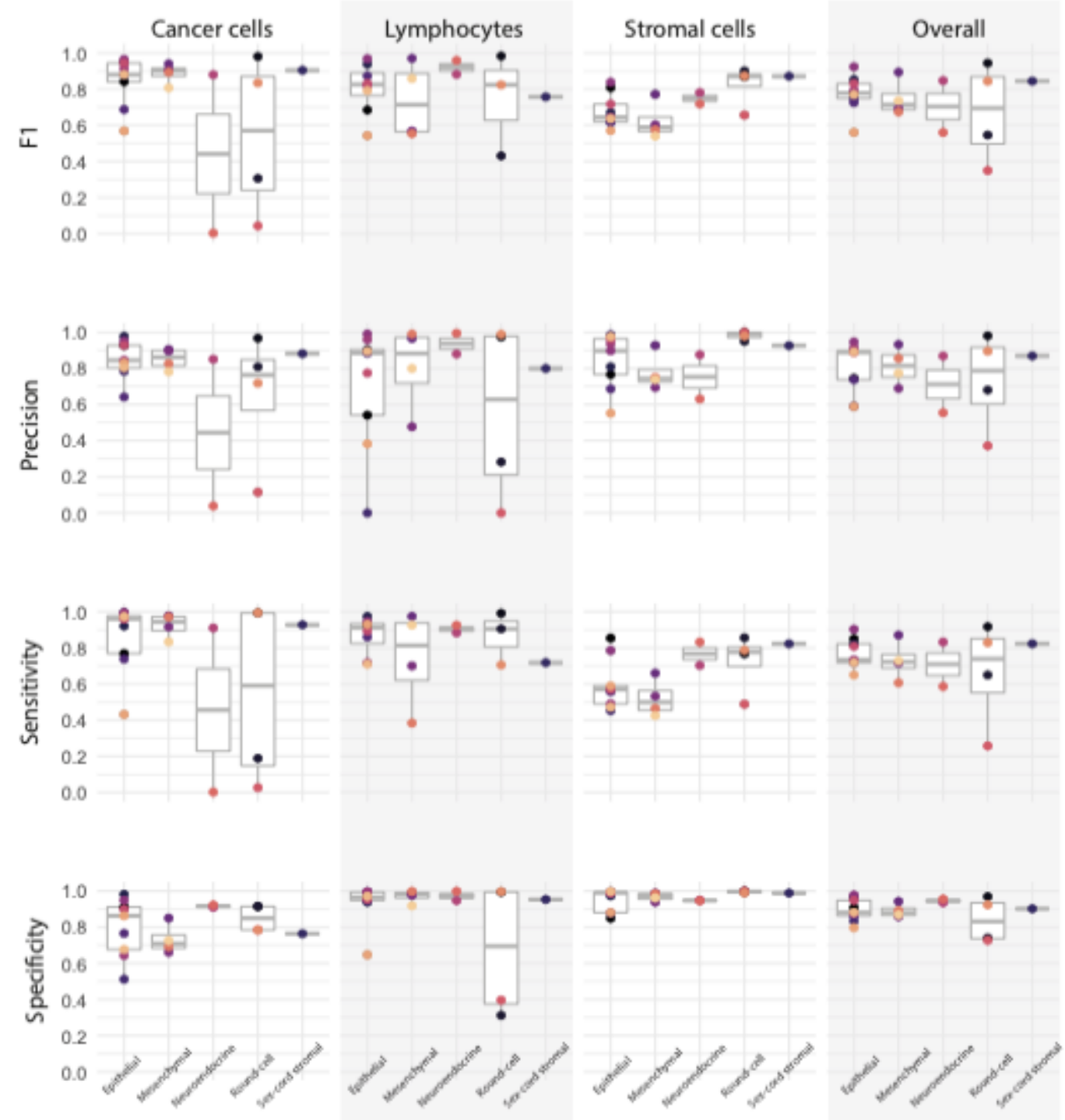

Tumour type

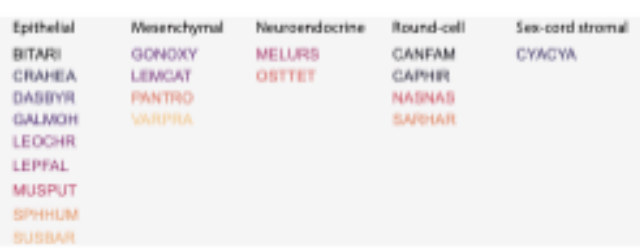

\section{Supplementary Figure 2 Extended Al prediction variability for inter and intra- species} tumour microenvironment cells. For each species, four metrics were evaluated including F1, precision, sensitivity and specificity (rows) for the prediction accuracy of cancer, lymphocyte and stromal cells as well as their average shown as 'overall' (columns). Species are grouped according to their tumour type and are labelled with their codes, for more species information, see Table 1. 
bioRxiv preprint doi: https://doi.org/10.1101/2022.03.05.482261; this version posted March 7, 2022. The copyright holder for this preprint (which was not certified by peer review) is the author/funder, who has granted bioRxiv a license to display the preprint in perpetuity. It is made available under aCC-BY-NC-ND 4.0 International license.

A

Cumulative explained variance

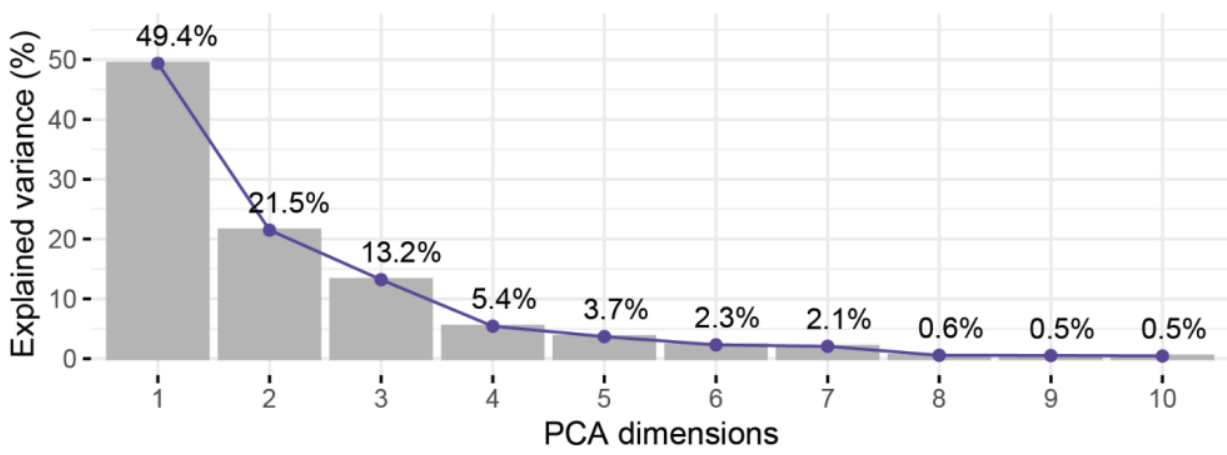

B

Contributions (\%) PC1

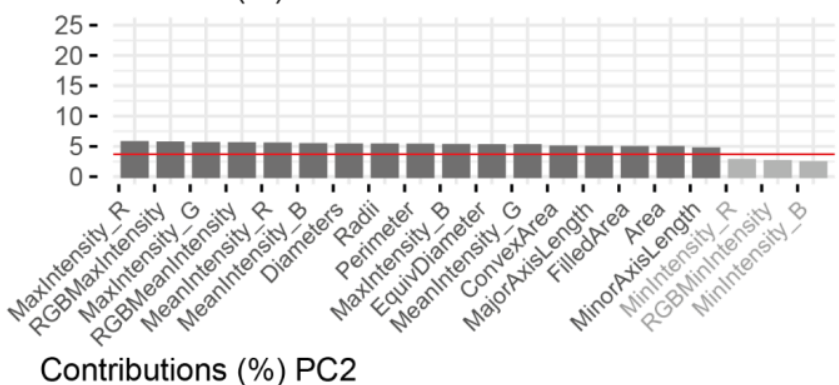

Contributions (\%) PC2

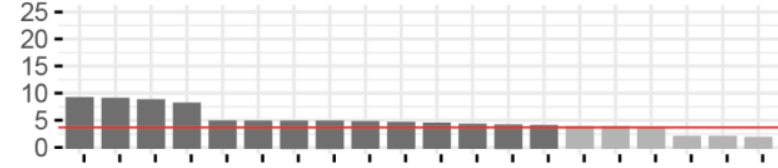
B. 0 \& 0

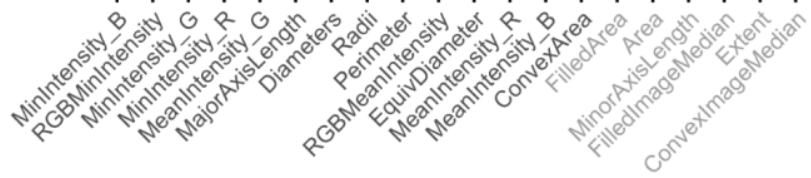

Contributions (\%) PC3
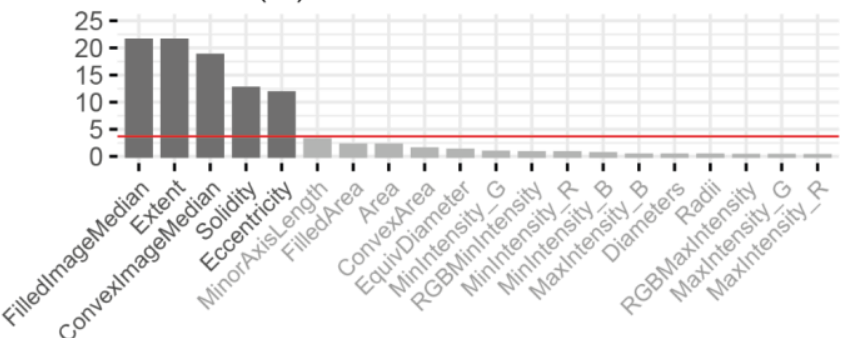

C

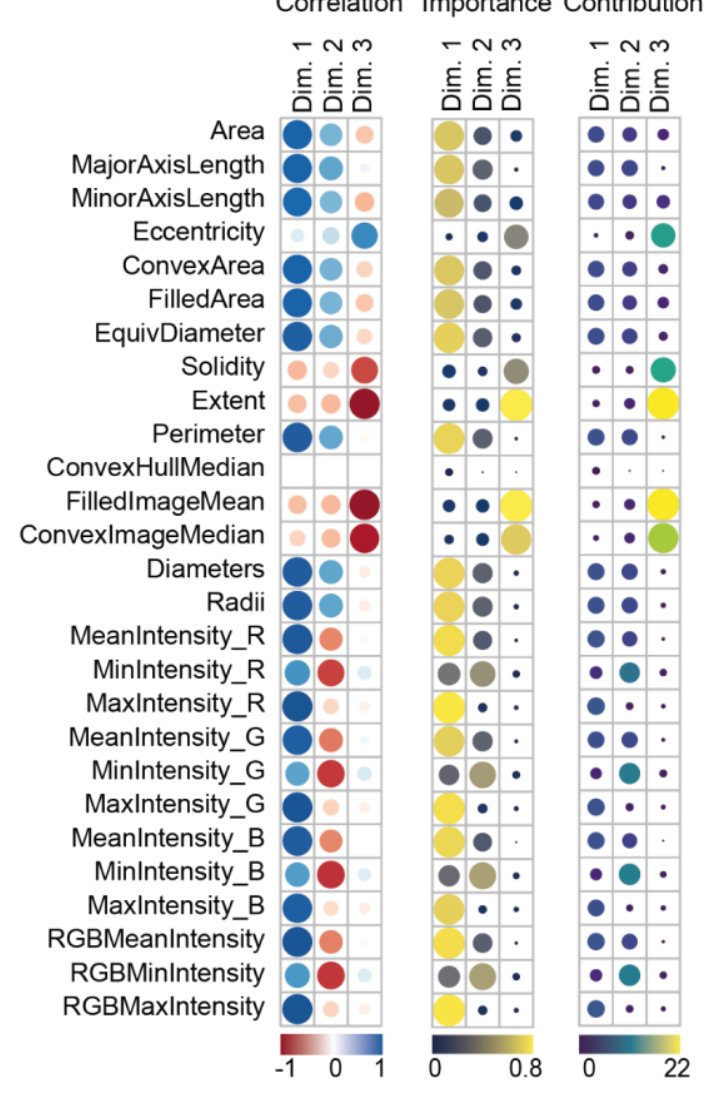

Supplementary Figure 3 Analysis of the morphological space. (A) Dimensions of the principal component analysis (PCA) and their explained variances. (B) The highest 20 contributions to PCA dimensions' explained variances. Darker bars are features above the mean contribution (red line). (C) From left to right, correlation, importance and contribution of the single-cell morphological features to PCA dimension. 
Supplementary Table 1 Summary of sample preparation methods as provided from the Zoological Society of London's pathological archive.

\begin{tabular}{|l|l|l|l|}
\hline Case ID & $\begin{array}{l}\text { Species } \\
\text { code }\end{array}$ & Pathologists & Method \\
\hline B01/17 & MUSPUT & IZVG/RVC- DD & Biopsy: removed during surgery and formalin-fixed \\
\hline B02/18 & GALMOH & IZVG/RVC- DD & Biopsy: removed during surgery and formalin-fixed \\
\hline B04/17 & LEMCAT & IZVG/RVC- MS & Biopsy: removed during surgery and formalin-fixed \\
\hline B07-8/04 & PANTRO & ZSL- AP & Biopsy - removed during surgery and formalin-fixed \\
\hline B09/04 & DASBYR & ZSL- AP & Biopsy - removed during surgery and formalin-fixed \\
\hline W17M035 & MELURS & IZVG/RVC- MS & $\begin{array}{l}\text { Euthanasia: Carcass fresh - PM examination one day after } \\
\text { death }\end{array}$ \\
\hline W17R187 & OSTTET & IZVG/RVC- DD & Natural death: Carcass fresh - PM on day of death \\
\hline ZA1360/15 & LEPFAL & IZVG/RVC- MS & $\begin{array}{l}\text { Natural death: Carcass slightly autolysed - PM on day of } \\
\text { death }\end{array}$ \\
\hline ZB017/18 & CYACYA & IZVG/RVC- MS & $\begin{array}{l}\text { Euthanasia: Carcass fresh - PM examination one day after } \\
\text { death }\end{array}$ \\
\hline ZB485/19 & SPHHUM & IZVG/RVC- CS & $\begin{array}{l}\text { Euthanasia: No comment on carcass condition - PM carried } \\
\text { out 2 days after euthanasia }\end{array}$ \\
\hline ZM134/17 & CAPHIR & IZVG/RVC- CS & Carcass fresh - euthanised and PM'd on day of death \\
\hline ZM138/17 & SUSBAR & IZVG/RVC- MS & Carcass fresh - PM on day of death \\
\hline ZM203/17 & LEOCHR & IZVG/RVC- MS & Carcass fresh - PM on day of death \\
\hline ZM633/18 & CRAHEA & IZVG/RVC- DD & $\begin{array}{l}\text { Euthanasia: Carcass fresh - PM examination one day after } \\
\text { death }\end{array}$ \\
\hline ZR1145/15 & GONOXY & IZVG/RVC- MS & $\begin{array}{l}\text { Euthanasia: Carcass fresh - kept in fridge two days before } \\
\text { examination }\end{array}$ \\
\hline & NASNAS & IZVG/RVC- CS & $\begin{array}{l}\text { Euthanasia: Carcass fresh - PM examination one day after } \\
\text { Leath }\end{array}$ \\
\hline
\end{tabular}


bioRxiv preprint doi: https://doi.org/10.1101/2022.03.05.482261; this version posted March 7, 2022. The copyright holder for this preprint (which was not certified by peer review) is the author/funder, who has granted bioRxiv a license to display the preprint in perpetuity. It is made available under aCC-BY-NC-ND 4.0 International license.

\begin{tabular}{|l|l|l|l|}
\hline ZR1148/18 & VARPRA & IZVG/RVC- DD & $\begin{array}{l}\text { Euthanasia: Carcass fresh - PM examination one day after } \\
\text { death }\end{array}$ \\
\hline ZR474/19 & BITARI & IZVG/RVC- CS & $\begin{array}{l}\text { Euthanasia: Carcass fresh - PM examination one day after } \\
\text { death }\end{array}$ \\
\hline
\end{tabular}


bioRxiv preprint doi: https://doi.org/10.1101/2022.03.05.482261; this version posted March 7, 2022. The copyright holder for this preprint (which was not certified by peer review) is the author/funder, who has granted bioRxiv a license to display the preprint in perpetuity. It is made available under aCC-BY-NC-ND 4.0 International license.

\section{Supplementary Table 2 The 27 single-cell features extracted to compute the morphological space.}

\begin{tabular}{|c|c|}
\hline Feature & Description \\
\hline Area & Two-dimensional extension of a shape \\
\hline MajorAxisLength & Longest diameter \\
\hline MinorAxisLength & Shortest diameter \\
\hline Eccentricity & Magnitude inversely related to shape curvature \\
\hline ConvexArea & Area resulting from connecting the external points of the shape \\
\hline FilledArea & Area of a corresponding image with holes filled in \\
\hline EquivDiameter & Diameter of a circle with the same area as the region \\
\hline Solidity & Extent to which the shape fills the convex area \\
\hline Extent & Ratio of pixels in the region to pixels in the total bounding box \\
\hline Perimeter & Length of the shape boundary \\
\hline ConvexHullMean & Smallest convex polygon that can contain the region \\
\hline FilledlmageMean & Average of pixels corresponding to the segmented mask, with all holes filled \\
\hline ConvexImageMean & Average of pixels corresponding to a segmented mask which specifies the convex hull of the region \\
\hline Diameters & Cell diameter using major and minor axes \\
\hline Radii & Cell radius \\
\hline MeanIntensity_R & Mean pixel intensity in the red channel \\
\hline Minlntensity_R & Minimum pixel intensity in the red channel \\
\hline MaxIntensity_R & Maximum pixel intensity in the red channel \\
\hline
\end{tabular}


bioRxiv preprint doi: https://doi.org/10.1101/2022.03.05.482261; this version posted March 7. 2022. The copyright holder for this preprint (which was not certified by peer review) is the author/funder, who has granted bioRxiv a license to display the preprint in perpetuity. It is made available under aCC-BY-NC-ND 4.0 International license.

\begin{tabular}{|l|l|}
\hline MeanIntensity_G & Mean pixel intensity in the green channel \\
\hline MinIntensity_G & Minimum pixel intensity in the green channel \\
\hline MaxIntensity_G & Maximum pixel intensity in the green channel \\
\hline MeanIntensity_B & Mean pixel intensity in the blue channel \\
\hline MinIntensity_B & Minimum pixel intensity in the blue channel \\
\hline MaxIntensity_B & Maximum pixel intensity in the blue channel \\
\hline RGBMeanIntensity & Mean pixel intensity in the composed image \\
\hline RGBMinIntensity & Minimum pixel intensity in the composed image \\
\hline RGBMaxIntensity & Maximum pixel intensity in the composed image \\
\hline
\end{tabular}


Supplementary table 3 Morphological volumes overlap of human cells on non-human cells' morphological space calculated by the three methods. The highest overlap values for nonhuman lymphocytes and tumour cells are bold-faced.

\begin{tabular}{|l|l|r|r|r|}
\hline $\begin{array}{c}\text { Morphological } \\
\text { volume of }\end{array}$ & \multicolumn{1}{|c|}{$\begin{array}{c}\text { Covered by the } \\
\text { volume of }\end{array}$} & $\begin{array}{c}\text { \% Overlap } \\
\text { (product) }\end{array}$ & $\begin{array}{c}\text { \% Overlap } \\
\text { (mean) }\end{array}$ & $\begin{array}{r}\text { \% Overlap } \\
\text { (geom. mean) }\end{array}$ \\
\hline $\begin{array}{l}\text { Non-human } \\
\text { lymphocytes }\end{array}$ & $\begin{array}{l}\text { Human } \\
\text { lymphocytes }\end{array}$ & $\mathbf{6 3 . 4 7}$ & $\mathbf{8 4 . 5 5}$ & $\mathbf{8 1 . 2 5}$ \\
\hline $\begin{array}{l}\text { Non-human } \\
\text { lymphocytes }\end{array}$ & $\begin{array}{l}\text { Human tumour } \\
\text { cells }\end{array}$ & 40.41 & 54.6 & 59.84 \\
\hline $\begin{array}{l}\text { Non-human } \\
\text { tumour cells }\end{array}$ & $\begin{array}{l}\text { Human } \\
\text { lymphocytes }\end{array}$ & 16.56 & $\mathbf{8 6 . 4 9}$ & 50.24 \\
\hline $\begin{array}{l}\text { Non-human } \\
\text { tumour cells }\end{array}$ & $\begin{array}{l}\text { Human tumour } \\
\text { cells }\end{array}$ & $\mathbf{6 7 . 9 7}$ & $\mathbf{8 6 . 1 4}$ \\
\hline
\end{tabular}

